\title{
Toplu Taşıma Kullanımının İkili Lojistik Regresyonu ile Karşılaştırmalı Analizi
}

\author{
Nuriye KABAKUŞ ${ }^{1}$, Ahmet TORTUM ${ }^{1}$
}

ÖZET: Bu çalışmanın amacı farklı gelişmişlik düzeyine sahip illerde yaşayan bireylerin toplu taşıma kullanımına etki eden faktörlerin belirlenmesidir. Çalışma kapsamında Türkiye'de gelişmişlik indeksine göre gelişmiş, gelişmekte olan ve gelişmemiş il gruplarından seçilen sırasıyla Ankara, Erzurum ve Bayburt illeri çalışma alanı olarak belirlenmiştir. Bu üç ilin merkez ilçe nüfuslarına göre örneklem büyüklükleri hesaplanmıştır. Çalışma alanlarında Şubat- Nisan 2015 tarihleri arasında saha çalışması yaptırılarak hanehalkı ulaşım anketleri uygulanmıştır. Hanehalkı ulaşım anketleri sonucu elde edilen veri seti çalışmanın amacına uygun olarak hazırlanmış ve oluşturulacak istatistiksel modelin değişkenleri belirlenmiştir. Bağımlı değişken olarak toplu taşıma kullanımı seçilmiştir. Bağımlı değişken nitel ve ikili cevap (evet-hayır, var-yok) içerdiği için ikili lojistik regresyon analizi uygulanmıştır. Modelde bağımsız değişken olarak cinsiyet, yaş, eğitim durumu, sürücü belgesi sahipliği, yolculuk amacı, yolculuk süresi gibi değişkenler kullanılmışır. Sonuç olarak, üç farklı gelişmişlik düzeyindeki iller için ayrı ayrı oluşturulan toplu taşıma kullanım ikili lojistik regresyon modeli sonuçları karşılaştırılmışır. Toplu taşıma kullanımında Ankara ilinde ehliyet sahipliği, yolculuk amacı, yolculuk süresi değişkenleri, Erzurum ilinde eğitim durumu, ehliyet sahipliği, yolculuk amacı, yolculuk süresi değişkenleri, Bayburt ilinde ise cinsiyet ve yolculuk süresi değişkenleri istatistiksel olarak anlamlı değişkenlerdir. Hanehalkı ulaşım anketlerinden elde edilen veriler sonucunda toplu taşıma kullanım oranı en yüksek olan il gelişmekte olan il grubundan seçilen Erzurum ili, toplu taşıma kullanım oranının en düşük olduğu il gelişmemiş il grubundan seçilen Bayburt ilidir.

Anahtar Kelimeler: İkili lojistik regresyon, toplu taşıma, gelişmiş-gelişmekte olan ve gelişmemiş il

\section{Comparative Analysis with Binary Logistic Regression of Using Public Transportation}

\begin{abstract}
The purpose of this study is to determine the parameters that affect the using of public transportation for individuals living in the cities which have the different level of development. Within the scope of the study according to the index of development Ankara, Erzurum, Bayburt are selected respectively as developed, developing, underdeveloped provinces in Turkey. The sample size is calculated using central district population of this provinces. Household transportation survey was applied doing a field study between February-April in 2015. The data set which is obtained from the result of the survey is suitable for the purpose of the study and variables of the statistical model are determined. Using public transportation is selected as dependent variables. Due to dependent variable has qualitative and binary response (yes-no, all-nothing) binary logistic regression analysis is applied. As independent variables sex, age, education level, ownership a driving license, trip purpose, trip time is chosen in this model. As a result, binary logistic regression model results which are composed separately for each the different three provinces are compared. The ownership of the driving license, trip purpose, trip time variables are the significant for using public transportation in Ankara, education level, ownership of the driving license, trip purpose, trip time are significant in Erzurum, gender, trip time are significant in Bayburt as statistically. While Erzurum which is selected from developing province group has the highest rate of using public transportation, Bayburt which is selected from underdeveloped province group has the lowest rate of using public transportation.
\end{abstract}

Keywords: Binary logistic regression, public transportation, developed- developing- underdeveloped

\footnotetext{
Nuriye KABAKUŞ (0000-0002-8479-6733), Ahmet TORTUM (0000-0002-5770-766X), Atatürk Üniversitesi, Mühendislik Fakültesi, İnşaat Mühendisliği, Erzurum, Turkey

Sorumlu yazar/Corresponding Author: Nuriye KABAKUŞ, nsirin@atauni.edu.tr
} 


\section{GíRiş}

Ülkemizde her geçen gün artan nüfus ve buna bağlı olarak artan araç sahipliği sebebiyle kentsel ulaşım problemleri de artmaktadır. Kent içi ulaşımda özellikle yolculuk talebinin fazla olduğu kentlerde toplu taşıma sistemlerinin kullanımı önemli avantajlar sağlamaktadır. $\mathrm{Bu}$ avantajlar; trafik de oluşabilecek tıkanıklığın azalması ve enerji tüketimi açısından çevreye verilen zararın azaltması olarak sıralanabilir.

Toplu taşıma sistemlerinin çekici hale getirilmesinde bu sistemlerin geliştirilmesi tek başına etkili olmamaktadır. Kentlerde diğer ulaşım türlerinin de planlanarak sistemlerinin birbiri ile koordineli hale getirilmesi gerekmektedir.Özellikle trafik tıkanıklığının yaşandığı büyük kentlerde otomobil kullanımını azaltmak, insanları toplu taşımaya yönlendirmek için toplu taşıma sistemlerinde yapılacak iyileştirmeler toplu taşımayı daha cazip hale getirebilir (Kılınçaslan, 2012). Toplu taşımayı destekleyen ulaşım türü yaklaşımlarının dünyadaki uygulamaları ulaşım politikası olarak günlük yaşama geçirilirse toplu taşıma kullanımı artırılabilir.

2015 yılında Buehler and Hamre tarafından yapılan çalışmada, Amerikalı yetişkinler arasında özel oto kullanımı, yürüme, bisiklet kullanımı ve toplu taşıma kullanımını incelemişlerdir. Öncelikle Batı Avrupa ülkelerine odaklanmışlar, 2001 ve 2009 Ulusal Hanehalkı Ulaşım Anketlerini çalışmalarında veri olarak kullanmışlardır. Bir haftalık yolculukları dikkate alarak 4 Amerikalı'dan 1'inin özel otomobil kullandığı sonucuna varmışlardır. Analizlerde Multinominal ve Lojistik Regresyon yöntemini kullanmışlardır. Sonuç olarak otomobil kullanımını azaltmaya yönelik politika değişikliklerini önermişlerdir (Buehler and Hamre, 2015). Bireylerin sürücü belgesine sahip olmaları ve bir arabaya kolayca erişebilmelerinin tüm yolculuklar için sürüş kolaylığg sağladığını ve diğer mod türlerini seçme olasılıklarını azalttığını vurgulamışlardır (Kuhnimhof et al., 2006). Norveç'te 2013 yılının Haziran - Ağustos aylarında yapmış olduğu anketlerle 1039 kişiye anket uygulamış eksik anketler çıkarılarak 546 anket üzerinden veri setini oluşturmuşlardır. $\mathrm{Bu}$ anket çalışması yardımıyla bireylerin toplu taşıma kullanımındaki amaçlarını, ulaşım mod seçimindeki tutumlarını, özel oto kullanım alışkanlıklarını, ulaşım önceliklerini karşılaştırmışlardır. Analizlerde yapısal eşitlik modelini kullanmışlar ve toplu taşıma kullanımını artırmaya yönelik trafik güvenlik kampanyalarına ve toplu taşımanın cazibesini artırmak için bu ulaşım türünün esnekliğini geliştirmeye odaklanabileceğini belirtmişlerdir (Şimşekoğlu et al., 2015). Toplu taşıma kullanımını etkileyen faktörleri ve toplu taşıma ile ilgili tutumlarda cinsiyet farklılıklarını değerlendirmeyi amaçlayarak, Ohio Devlet Üniversitesi'nde 2012 kampüs ulaşım anketinden toplanan verilerle bireylerin sosyo-demografik özellikleri, tür seçimleri, güvenilirlik, esneklik,erişilebilirlikvekonforolmaküzeretoplutaşıma kullanma yönündeki tutumları ölçülmüsştür. Analizlerde ikili lojit model kullanılmıştır. Çalışmanın sonucunda elde edilen bulgular ile toplu taşıma kullanımını ve cinsiyetler arasındaki farklılıkların nasıl etkilediğini ulaştırma planlamacılarının anlamalarına yardımcı olmaktadır (Namgung and Akar, 2014). Kennedy, Toronto bölgesinde özel ve toplu taşıma kullanımını derinlemesine karşılaştırmışlardır (Kennedy, 2002). Miller et al. 2016 yılında yapmış oldukları çalışmada toplu taşıma kullanımı ve sürdürülebilirlik arasındaki ilişkiyi incelemişlerdir (Miller et al., 2016).

Bu çalışmada Türkiye'de gelişmiş il grubundan Ankara, gelişmekte olan il grubundan Erzurum ve gelişmemiş il grubundan Bayburt ili çalışma alanı olarak seçilmiştir. Bu üç ilde merkez ilçe nüfuslarına göre örneklem büyüklükleri hesaplanarak hanehalkı ulaşım anketleri tabakalı örnekleme metodu kullanılarak yaptırılmıştır. Saha çalışmasına Şubat 2015 de başlanılmış ve Nisan 2015 de tamamlanmıştır. Elde edilen anketler ile veri tabanı oluşturulmuştur. Üç farklı gelişmişlik düzeyindeki Ankara, Erzurum ve Bayburt illerinde toplu taşıma kullanımı karşılaştırılmıştır. Çalışma sonucunda gelişmişlik seviyesi farklı olan üç il için oluşturulan ikili lojistik regresyon model sonuçları karşılaştırılmıştır.

\section{MATERYAL VE YÖNTEM}

\section{Materyal}

Çalışma alanı olarak Türkiye'de 3 il belirlenmiştir. Bunlardan birincisi Türkiye' nin başkenti olan Ankara ilidir. Ankara, Türkiye'nin merkezine yakın bir konuma sahip olup Türkiye' nin nüfusu bakımından ikinci büyük, yüzölçüm olarak da üçüncü büyük ilidir. İkinci çalışma alanı Erzurum, Doğu Anadolu Bölgesinin en büyük ili olup nüfusolarak27.ve yüzölçümolarak da4 . büyük ilidir. Üçüncü çalışma alanı Bayburt ili ise nüfus ve yüzölçüm olarak Türkiye'nin en küçük illerinden biridir. Çalışma alanı belirlenirken illerin gelişmişlik indekslerine göre karar verilmiştir (Çizelge 1). Çok gelişmiş il grubundan başkent Ankara, gelişmekte olan illerden Erzurum ve gelişmemiş illerden Bayburt seçilmiştir. 
Çizelge 1. 2012 Yılı İllerin Gelişmişlik Endekslerine Göre Gelişmişlik Grupları (Gül ve Çevik, 2014)

\begin{tabular}{|c|c|c|c|c|c|c|c|c|c|c|c|}
\hline & il & ige & & il & ige & & il & ige & & il & ige \\
\hline 1 & İstanbul & 36.56 & 22 & Hatay & 0.37 & 43 & Karaman & -1.08 & 64 & Kilis & -1.97 \\
\hline 2 & Ankara & 12.54 & 23 & Isparta & 0.23 & 44 & Rize & -1.10 & 65 & Çankırı & -1.98 \\
\hline 3 & İzmir & 8.84 & 24 & Çanakkale & 0.13 & 45 & Sivas & -1.12 & 66 & Van & -2.16 \\
\hline 4 & Antalya & 6.85 & 25 & Yalova & -0.05 & 46 & Burdur & -1.18 & 67 & Gümüşhane & -2.19 \\
\hline 5 & Bursa & 4.14 & 26 & Bolu & -0.09 & 47 & Şanlıurfa & -1.29 & 68 & Adiyaman & -2.22 \\
\hline 6 & Kocaeli & 3.40 & 27 & Edirne & -0.24 & 48 & Bartın & -1.43 & 69 & Yozgat & -2.28 \\
\hline 7 & Muğla & 2.64 & 28 & Elazı̆̆ & -0.51 & 49 & Kırşehir & -1.44 & 70 & Bayburt & -2.34 \\
\hline 8 & Adana & 2.09 & 29 & Kütahya & -0.54 & 50 & Amasya & -1.47 & 71 & Kars & -2.39 \\
\hline 9 & Konya & 2.07 & 30 & Zonguldak & -0.56 & 51 & Tokat & -1.47 & 72 & Tunceli & -2.47 \\
\hline 10 & Gaziante & 1.79 & 31 & Kırklareli & -0.64 & 52 & Çorum & -1.48 & 73 & Şırnak & -2.54 \\
\hline 11 & Eskişehir & 1.74 & 32 & Malatya & -0.77 & 53 & Ordu & -1.55 & 74 & Bingöl & -2.67 \\
\hline 12 & Denizli & 1.28 & 33 & Nevşehir & -0.89 & 54 & Aksaray & -1.56 & 75 & Siirt & -2.72 \\
\hline 13 & Mersin & 1.26 & 34 & Afyon & -0.90 & 55 & Erzincan & -1.57 & 76 & Iğdır & -2.91 \\
\hline 14 & Kayseri & 1.17 & 35 & Erzurum & -0.91 & 56 & Artvin & -1.62 & 77 & Muş & -2.98 \\
\hline 15 & Trabzon & 0.76 & 36 & Kahramanmar & -0.96 & 57 & Osmaniye & -1.63 & 78 & Bitlis & -3.02 \\
\hline 16 & Tekirdağ & 0.65 & 37 & Düzce & -0.96 & 58 & Kastamonu & -1.64 & 79 & Ağrı & -3.02 \\
\hline 17 & Sakarya & 0.52 & 38 & Karabük & -0.97 & 59 & Giresun & -1.71 & 80 & Ardahan & -3.04 \\
\hline 18 & Balıkesir & 0.49 & 39 & Uşak & -0.98 & 60 & Niğde & -1.73 & 81 & Hakkari & -3.15 \\
\hline 19 & Samsun & 0.43 & 40 & Kırıkkale & -1.01 & 61 & Batman & -1.80 & & & \\
\hline 20 & Manisa & 0.39 & 41 & Diyarbakır & -1.05 & 62 & Sinop & -1.84 & & & \\
\hline 21 & Aydın & 0.37 & 42 & Bilecik & -1.06 & 63 & Mardin & -1.86 & & & \\
\hline
\end{tabular}

\section{Gelişmiş}

Çalışma alanları için örneklem büyüklükleri denklem 1 aracılığı ile hesaplanmıştır. Bu üç ilde merkez ilçelerde tabakalı rassal örnekleme metodu kullanılarak hanehalkı ulaşım anketleri yaptırılmış ve çalışma kapsamında kullanılacak veri seti oluşturulmuştur.

\section{Evrendeki eleman sayısı biliniyorsa}

$$
n=\frac{N \cdot p \cdot q \cdot z^{2} \alpha / 2}{(N-1) d^{2}+p \cdot q \cdot z^{2} \alpha / 2}
$$


Formülde;

$\mathrm{N}=$ Evrendeki birey sayısı (İlerin nüfusu, Çizelge 2), $n=$ örnekleme alınacak birey sayısı, $p=$ incelenecek olayın görüş sıklığ1 $(0.5)$, q=incelenecek olayın görülmeyiş sıklığ $(1-p=0.5), \quad z=$ Saptanan güven düzeyinden $\mathrm{z}$ çizelgesindan bulunan teorik değer (1.96),
d=Olayın görülme sıklığına göre yapılmak istenen \pm sapma (0.05) olarak simgelenmiştir.

İllerin merkez ilçe nüfusları, hesaplanan örneklem büyüklükleri (Eşitlik 1), anketin uygulandı̆̆ hane sayısı ve hanedeki kişi sayısı Çizelge 2' de sunulmuştur.

Çizelge 2. İllerin Merkez İlçe Nüfusları, Örneklem Büyüklüğü ve Uygulanan Anket Sayısı

\begin{tabular}{|l|c|c|c|c|}
\hline \multicolumn{1}{|c|}{ İ } & Nüfus* & Örneklem Büyüklüğ̈̈ & $\begin{array}{c}\text { Anket uygulanan } \\
\text { hane sayısı }\end{array}$ & $\begin{array}{c}\text { Hanedeki toplam } \\
\text { kişi sayısı }\end{array}$ \\
\hline Ankara & 4822839 & 384.12 & 603 & 1989 \\
\hline Erzurum & 399683 & 383.79 & 410 & 1839 \\
\hline Bayburt & 63848 & 380.37 & 385 & 1568 \\
\hline
\end{tabular}

* Merkez ilçe nüfusları 2014

Toplu taşıma kullanımı bağımlı değişken, cinsiyet, yaş, eğitim durumu, sürücü belgesi sahipliği, yolculuk amacı, yolculuk süresi değişkenleri de kategorik bağımsız değişken olarak ikili lojistik regresyon

\section{Yöntem}

$\mathrm{Bu}$ çalışmada kullanılan veri seti, gelişmiş, gelişmekte olan ve gelişmemiş illerde hanelerde uygulanan hanehalkı ulaşım anketleri yardımıyla elde edilen verilerden oluşmaktadır. Modelde bağımlı

$$
L=\ln \left[\frac{p_{i}}{1-p_{i}}\right]=b_{0}+b_{1} X_{i}+e_{i}
$$

Lojistik regresyon modelinin parametreleri, analitik olarak elde edilemediğinden, tahmin tekniği olarak maksimum olabilirlik tekniği kullanılır (Field,2005; Kalayc1, 2008).

\section{BULGULAR VE TARTIŞMA}

$\mathrm{Bu}$ çalışmada verilerin değerlendirilmesi SPSS 20 paket programında yapılmıştır. Lojistik Regresyon analizi yapılarak ikili lojistik regresyon model modelde veri seti olarak kullanılmıştır. Kategorik bağımsız değişken için son kategoriler referans kategori olarak seçilmiştir.

değişken olarak seçilen toplu taşıma kullanımı nitel değişken olduğu ve ikili cevap (evet-hayır) içerdiğinden dolayı ikili lojistik regresyon analizi uygulanmıştır.

Lojistik regresyon modeli aşağıdaki matematiksel ifade ile formüle edilebilir (Kalaycı, 2008).

yardımıyla hanehalkının toplu taşıma tercihlerinde etkili olan faktörlerin neler olduğu ve farklı gelişmişlik düzeyindeki illerde toplu taşıma kullanımı belirlenerek karşılaştırılmıştır.

Anketlerden elde edilen veriler doğrultusunda çalışma alanındaki iller için toplu taşıma kullanım oranları Çizelge 3'de verilmiştir. Toplu taşıma kullanım oranının \% 41.5 olduğu en yüksek olduğu il gelişmekte olan Erzurum ilidir (Şekil 1). 
Çizelge 3. İllerin Toplu Taşıma Kullanımı

\begin{tabular}{|l|c|c|c|c|c|c|}
\hline İller & \multicolumn{2}{|c|}{ Ankara } & \multicolumn{2}{c|}{ Erzurum } & \multicolumn{2}{c|}{ Bayburt } \\
\hline Toplu taşıma kullanma durumu & Frekans & Yüzde & Frekans & Yüzde & Frekans & Yüzde \\
\hline Toplu taşıma kullanan & 577 & 30.2 & 572 & 41.5 & 173 & 14.8 \\
\hline Toplu taşıma kullanmayan & 1332 & 69.8 & 805 & 58.5 & 996 & 85.2 \\
\hline Toplam & 1909 & 100 & 1377 & 100 & 1169 & 100 \\
\hline
\end{tabular}

- Toplu Taşıma Kullanan e Toplu Taşıma Kullanmayan

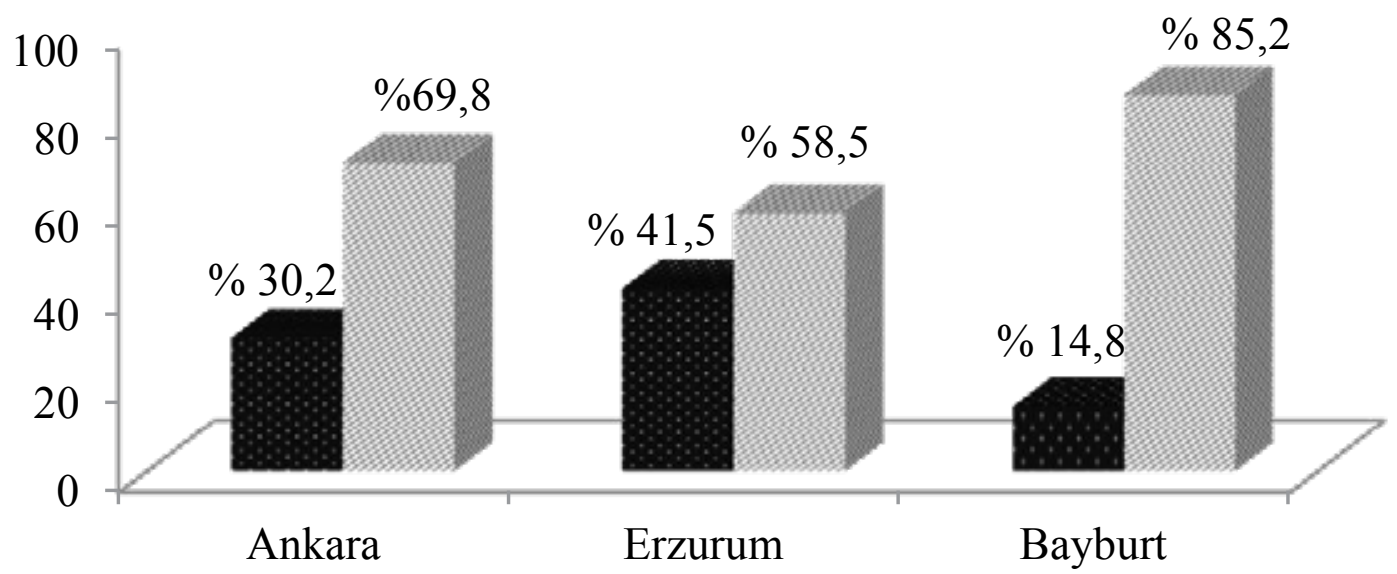

Şekil 1. İllerin Toplu Taşıma Kullanım Dağılımı

Toplu taşıma kullanımı için oluşturulan ikili lojistik regresyon model sonuçları incelendiğinde, Ankara ilinde sürücü belgesi sahipliği, yolculuk amacı, yolculuk süresi bağımsız değişkenleri \% 5 anlamlılık seviyesinde istatistiksel olarak anlamlı (sig.<0.05) bulunmuştur (Çizelge 4). Çizelge 4 incelendiğinde Ankara ilinde sürücü belgesi sahibi olmayanların sürücü belgesi olanlara göre toplu taşıma kullanma ihtimali 2.034 kat daha fazladır.

Toplu taşıma kullanma ihtimali, yolculuk amacı ev olanların yolculuk amacı diğer kategorisine göre 21.928 kat, yolculuk amacı iş olanların yolculuk amacı diğer kategorisine göre 4.408 kat, yolculuk amacı eğitim olanların yolculuk amacı diğer kategorisine göre 6.694 kat, yolculuk amacı sağlık olanların yolculuk amacı diğer kategorisine göre 2 kat, yolculuk amacı alışveriş olanların yolculuk amacı diğer kategorisine göre 0.561 kat, yolculuk amacı iş takibi olanların yolculuk amacı diğer kategorisine göre 1.42 kat, yolculuk amacı akraba ziyareti olanların yolculuk amacı diğer kategorisine göre 1.947 kat daha fazladır.

Yolculuk süresi 0-5 dk arasında olanların yolculuk süresi $60 \mathrm{dk}$ ve üzeri olanlara göre toplu taşıma kullanma ihtimali $0.012 \mathrm{~kat}$, yolculuk süresi $6-11 \mathrm{dk}$ arasında olanların yolculuk süresi $60 \mathrm{dk}$ ve üzeri olanlara göre toplu taşıma kullanma ihtimali 0.049 kat, yolculuk süresi 12-17 dk arasında olanların yolculuk süresi $60 \mathrm{dk}$ ve üzeri olanlara göre toplu taşıma kullanma ihtimali 0.07 kat, yolculuk süresi $18-23 \mathrm{dk}$ arasında olanların yolculuk süresi $60 \mathrm{dk}$ ve üzeri olanlara göre toplu taşıma kullanma ihtimali 0.152 kat, yolculuk süresi 24$29 \mathrm{dk}$ arasında olanların yolculuk süresi $60 \mathrm{dk}$ ve üzeri olanlara göre toplu taşıma kullanma ihtimali 0.247 kat, yolculuk süresi 30-35 dk arasında olanların yolculuk süresi $60 \mathrm{dk}$ ve üzeri olanlara göre toplu taşıma kullanma ihtimali 0.370 kat daha fazladır. 
Çizelge 4. Ankara ili için ikili lojistik regresyon model sonuçları

\begin{tabular}{|c|c|c|c|c|c|c|}
\hline Değişkenler & B & S.E. & Wald & df & Sig. & $\operatorname{Exp}(B)$ \\
\hline \multicolumn{7}{|l|}{ Cinsiyet } \\
\hline Kadın & 0.112 & 0.137 & 0.666 & 1 & 0.415 & 1.119 \\
\hline Erkek & \multicolumn{6}{|c|}{ Referans Kategori } \\
\hline Yaşı & & & 4.366 & 5 & 0.498 & \\
\hline $0-11$ & -0.213 & 0.456 & 0.218 & 1 & 0.640 & 0.808 \\
\hline $12-23$ & 0.336 & 0.382 & 0.770 & 1 & 0.380 & 1.399 \\
\hline $24-35$ & 0.180 & 0.358 & 0.253 & 1 & 0.615 & 1.197 \\
\hline $36-47$ & 0.246 & 0.359 & 0.469 & 1 & 0.493 & 1.279 \\
\hline $48-59$ & 0.069 & 0.378 & 0.033 & 1 & 0.855 & 1.071 \\
\hline $60>$ & \multicolumn{6}{|c|}{ Referans Kategori } \\
\hline Ĕ̆itimdurumu & & & 6.113 & 8 & 0.635 & \\
\hline Çocuk-kreş & -1.068 & 1.261 & 0.717 & 1 & 0.397 & 0.344 \\
\hline Okur yazar değil & -0.375 & 1.687 & 0.049 & 1 & 0.824 & 0.688 \\
\hline Okur Yazar & -1.192 & 1.593 & 0.560 & 1 & 0.454 & 0.304 \\
\hline İlkokul & -1.239 & 1.172 & 1.118 & 1 & 0.290 & 0.290 \\
\hline Ortaokul & -1.238 & 1.172 & 1.116 & 1 & 0.291 & 0.290 \\
\hline Lise & -0.981 & 1.159 & 0.716 & 1 & 0.397 & 0.375 \\
\hline Üniversite & -0.979 & 1.160 & 0.713 & 1 & 0.399 & 0.376 \\
\hline Yüksekokul & -1.858 & 1.280 & 2.106 & 1 & 0.147 & 0.156 \\
\hline Lisansüstü & \multicolumn{6}{|c|}{ Referans Kategori } \\
\hline \multicolumn{7}{|c|}{ Sürücü Belgesi Sahipliği } \\
\hline SB yok & 0.710 & 0.174 & 16.620 & 1 & 0.000 & 2.034 \\
\hline SB var & \multicolumn{6}{|c|}{ Referans Kategori } \\
\hline Yolculuk amacı & & & 91.350 & 7 & 0.000 & \\
\hline Ev & 3.088 & 0.748 & 17.029 & 1 & 0.000 & 21.928 \\
\hline İş & 1.483 & 0.241 & 37.803 & 1 & 0.000 & 4.408 \\
\hline Eğitim & 1.901 & 0.278 & 46.661 & 1 & 0.000 & 6.694 \\
\hline Sağlık & 0.693 & 0.467 & 2.200 & 1 & 0.138 & 2.000 \\
\hline Alişveriş & -0.578 & 0.400 & 2.087 & 1 & 0.149 & 0.561 \\
\hline İş Takibi & 0.351 & 1.244 & 0.080 & 1 & 0.778 & 1.420 \\
\hline Akraba Ziyareti & 0.666 & 0.385 & 2.987 & 1 & 0.084 & 1.947 \\
\hline Diğer & \multicolumn{6}{|c|}{ Referans Kategori } \\
\hline Yolculuksüresi & & & 268.316 & 10 & 0.000 & \\
\hline 0-5 Dakika & -4.412 & 0.420 & 110.079 & 1 & 0.000 & 0.012 \\
\hline 6-11 Dakika & -3.021 & 0.333 & 82.147 & 1 & 0.000 & 0.049 \\
\hline 12-17 Dakika & -2.665 & 0.329 & 65.530 & 1 & 0.000 & 0.070 \\
\hline 18-23 Dakika & -1.882 & 0.323 & 33.883 & 1 & 0.000 & 0.152 \\
\hline 24-29 Dakika & -1.400 & 0.367 & 14.568 & 1 & 0.000 & 0.247 \\
\hline 30-35 Dakika & -0.994 & 0.324 & 9.430 & 1 & 0.002 & 0.370 \\
\hline 36-41 Dakika & -0.110 & 0.424 & 0.067 & 1 & 0.796 & 0.896 \\
\hline 42-47 Dakika & -0.459 & 0.386 & 1.414 & 1 & 0.234 & 0.632 \\
\hline 48-53 Dakika & 20.369 & 9498.279 & 0.000 & 1 & 0.998 & $\begin{array}{l}701469 \\
790.48 \\
\end{array}$ \\
\hline 54-50 Dakika & 19.849 & 17922.130 & 0.000 & 1 & 0.999 & $\begin{array}{l}417027 \\
348.56 \\
\end{array}$ \\
\hline $60>$ Dakika & \multicolumn{6}{|c|}{ Referans Kategori } \\
\hline Sabit & 0.479 & 1.250 & 0.147 & 1 & 0.701 & 1.615 \\
\hline
\end{tabular}

(B: Regresyon Katsayıları, S.E.: Standart Hata, Wald: istatistiği, df: serbestlik derecesi, sig.: anlamlılık düzeyi, Exp(B): üstel B değerleri) 
Toplu taşıma kullanımı için oluşturulan ikili lojistik regresyon model sonuçları incelendiğinde, Erzurum ilinde eğitim durumu, sürücü belgesi sahipliği, yolculuk amacı, yolculuk süresi bağımsız değişkenleri $\% 5$ anlamlılık seviyesinde istatistiksel olarak anlamlı (sig.<0.05) bulunmuştur (Çizelge 5).

Çizelge 5. Erzurum ili için ikili lojistik regresyon model sonuçları

\begin{tabular}{|c|c|c|c|c|c|c|}
\hline Değişkenler & \multirow[t]{2}{*}{ B } & S.E. & \multirow[t]{2}{*}{ Wald } & \multirow[t]{2}{*}{ df } & \multirow[t]{2}{*}{ Sig. } & \multirow[t]{2}{*}{$\operatorname{Exp}(B)$} \\
\hline Cinsiyet & & & & & & \\
\hline Kadın & 0.196 & 0.150 & 1.701 & 1 & 0.192 & 1.217 \\
\hline Erkek & \multicolumn{6}{|c|}{ Referans Kategori } \\
\hline Yaşı & & & 2.280 & 5 & 0.809 & \\
\hline $0-11$ & -0.810 & 0.596 & 1.846 & 1 & 0.174 & 0.445 \\
\hline $12-23$ & -0.599 & 0.554 & 1.168 & 1 & 0.280 & 0.550 \\
\hline $24-35$ & -0.490 & 0.550 & 0.795 & 1 & 0.373 & 0.612 \\
\hline $36-47$ & -0.401 & 0.545 & 0.541 & 1 & 0.462 & 0.670 \\
\hline $48-59$ & -0.478 & 0.544 & 0.773 & 1 & 0.379 & 0.620 \\
\hline $60>$ & \multicolumn{6}{|c|}{ Referans Kategori } \\
\hline Ĕ̆itimdurumu & & & 39.486 & 8 & 0.000 & \\
\hline Çocuk-kreş & -0.583 & 1.531 & 0.145 & 1 & 0.703 & 0.558 \\
\hline Okur yazar değil & 0.742 & 1.341 & 0.306 & 1 & 0.580 & 2.100 \\
\hline Okur Yazar & -0.457 & 1.577 & 0.084 & 1 & 0.772 & 0.633 \\
\hline İlkokul & 0.577 & 1.080 & 0.285 & 1 & 0.593 & 1.780 \\
\hline Ortaokul & 0.768 & 1.077 & 0.509 & 1 & 0.476 & 2.156 \\
\hline Lise & 1.242 & 1.068 & 1.352 & 1 & 0.245 & 3.463 \\
\hline Üniversite & 1.856 & 1.066 & 3.035 & 1 & 0.082 & 6.399 \\
\hline Yüksekokul & 1.228 & 1.234 & 0.990 & 1 & 0.320 & 3.414 \\
\hline Lisansüstü & \multicolumn{6}{|c|}{ Referans Kategori } \\
\hline \multicolumn{7}{|c|}{ Sürücü Belgesi Sahipliŭi } \\
\hline SB yok & 0.402 & 0.178 & 5.108 & 1 & 0.024 & 1.495 \\
\hline SB var & \multicolumn{6}{|c|}{ Referans Kategori } \\
\hline Yolculuk amacı & & & 45.080 & 7 & 0.000 & \\
\hline Ev & 1.260 & 0.951 & 1.755 & 1 & 0.185 & 3.525 \\
\hline İş & 0.701 & 0.382 & 3.365 & 1 & 0.067 & 2.016 \\
\hline Eğitim & 1.740 & 0.388 & 20.096 & 1 & 0.000 & 5.700 \\
\hline Sağlık & 1.167 & 0.747 & 2.444 & 1 & 0.118 & 3.212 \\
\hline Alışveriş & 0.066 & 0.459 & 0.021 & 1 & 0.885 & 1.069 \\
\hline İş Takibi & -19.024 & 17384.75 & 0.000 & 1 & 0.999 & 0.000 \\
\hline Akraba Ziyareti & 0.837 & 0.536 & 2.438 & 1 & 0.118 & 2.310 \\
\hline Diğer & \multicolumn{6}{|c|}{ Referans Kategori } \\
\hline Yolculuksüresi & & & 146.641 & 9 & 0.000 & \\
\hline 0-5 Dakika & -2.109 & 0.398 & 28.130 & 1 & 0.000 & 0.121 \\
\hline 6-11 Dakika & -1.987 & 0.368 & 29.092 & 1 & 0.000 & 0.137 \\
\hline 12-17 Dakika & -1.113 & 0.356 & 9.755 & 1 & 0.002 & 0.329 \\
\hline 18-23 Dakika & -0.190 & 0.354 & 0.288 & 1 & 0.592 & 0.827 \\
\hline 24-29 Dakika & -0.257 & 0.441 & 0.340 & 1 & 0.560 & 0.773 \\
\hline 30-35 Dakika & -0.333 & 0.363 & 0.844 & 1 & 0.358 & 0.717 \\
\hline 36-41 Dakika & 1.781 & 0.835 & 4.551 & 1 & 0.033 & 5.935 \\
\hline 42-47 Dakika & 1.544 & 0.839 & 3.388 & 1 & 0.066 & 4.685 \\
\hline 48-53 Dakika & 0.322 & 1.180 & 0.075 & 1 & 0.785 & 1.380 \\
\hline $60>$ Dakika & \multicolumn{6}{|c|}{ Referans Kategori } \\
\hline Sabit & -1.649 & 1.266 & 1.697 & 1 & 0.193 & 0.192 \\
\hline
\end{tabular}

(B: Regresyon Katsayıları, S.E.: Standart Hata, Wald: istatistiği, df: serbestlik derecesi, sig.: anlamlılık düzeyi, Exp(B): üstel B değerleri) 
Çizelge 5 incelendiğinde, Erzurum ilinde eğitim değişkeni kategorisinden eğitim durumu kreş olanlar lisansüstü eğitim durumuna sahip olanlara göre 0.558 kat, eğitim durumu okur yazar olmayanlar lisansüstü eğitim durumuna sahip olanlara göre 2.1 kat, eğitim durumu okur yazar olanlar lisansüstü eğitim durumuna sahip olanlara göre 0.633 kat, eğitim durumu ilkokul olanlar lisansüstü eğitim durumuna sahip olanlara göre 1.780 kat, eğitim durumu ortaokul olanlar lisansüstü eğitim durumuna sahip olanlara göre 2.156 kat, eğitim durumu lise olanlar lisansüstü eğitim durumuna sahip olanlara göre 3.463 kat, eğitim durumu üniversite olanlar lisansüstü eğitim durumuna sahip olanlara göre 6.399 kat, eğitim durumu yüksekokul olanlar lisansüstü eğitim durumuna sahip olanlara göre 3.414 kat toplu taşıma kullanma ihtimalleri daha fazladır.

Erzurum ilinde sürücü belgesi sahibi olmayanların sürücü belgesi olanların göre toplu taşıma kullanma ihtimali 1.495 kat daha fazladır. Toplu taşıma kullanma ihtimali, yolculuk amacı ev olanların yolculuk amacı diğer kategorisine göre 3.525 kat, yolculuk amacı iş olanların yolculuk amacı diğer kategorisine göre 2.016 kat, yolculuk amacı eğitim olanların yolculuk amacı diğer kategorisine göre 5.7 kat, yolculuk amacı sağlık olanların yolculuk amacı diğer kategorisine göre 3.212 kat, yolculuk amacı alışveriş olanların yolculuk amacı diğer kategorisine göre 1.069 kat, yolculuk amacı akraba ziyareti olanların yolculuk amacı diğer kategorisine göre 2.31 kat daha fazladır.

Yolculuk süresi 0-5 $\mathrm{dk}$ arasında olanların yolculuk süresi $60 \mathrm{dk}$ ve üzeri olanlara göre toplu taşıma kullanma ihtimali 0.121 kat, yolculuk süresi 6-11 dk arasında olanların yolculuk süresi $60 \mathrm{dk}$ ve üzeri olanlara göre toplu taşıma kullanma ihtimali 0.137 kat, yolculuk süresi $12-17 \mathrm{dk}$ arasında olanların yolculuk süresi $60 \mathrm{dk}$ ve üzeri olanlara göre toplu taşıma kullanma ihtimali 0.329 kat, yolculuk süresi $18-23 \mathrm{dk}$ arasında olanların yolculuk süresi $60 \mathrm{dk}$ ve üzeri olanlara göre toplu taşıma kullanma ihtimali 0.827 kat, yolculuk süresi $24-29 \mathrm{dk}$ arasında olanların yolculuk süresi $60 \mathrm{dk}$ ve üzeri olanlara göre toplu taşıma kullanma ihtimali 0.773 kat, yolculuk süresi 30-35 dk arasında olanların yolculuk süresi $60 \mathrm{dk}$ ve üzeri olanlara göre toplu taşıma kullanma ihtimali 0.717 kat, yolculuk süresi 36-41 dk arasında olanların yolculuk süresi $60 \mathrm{dk}$ ve üzeri olanlara göre toplu taşıma kullanma ihtimali 5.935 kat, yolculuk süresi 42-47 dk arasında olanların yolculuk süresi $60 \mathrm{dk}$ ve üzeri olanlara göre toplu taşıma kullanma ihtimali $4.685 \mathrm{~kat}$, yolculuk süresi $48-53 \mathrm{dk}$ arasında olanların yolculuk süresi $60 \mathrm{dk}$ ve üzeri olanlara göre toplu taşıma kullanma ihtimali 1.380 kat daha fazladir.

Toplu taşıma kullanımı için oluşturulan ikili lojistik regresyon model sonuçları incelendiğinde, Bayburt ilinde cinsiyet ve yolculuk süresi bağımsız değişkenleri \% 5 anlamlılık seviyesinde istatistiksel olarak anlamlı (sig.<0.05) bulunmuştur (Çizelge 6).

Çizelge 6 incelendiğinde Bayburt ilinde cinsiyeti Kadın olanların erkeklere göre toplu taşıma kullanma ihtimali 1.901 kat daha fazladır. Yolculuk süresi 0-5 dk arasında olanların yolculuk süresi 60 dk ve üzeri olanlara göre toplu taşıma kullanma ihtimali 0.337 kat, yolculuk süresi 6-11 dk arasında olanların yolculuk süresi $60 \mathrm{dk}$ ve üzeri olanlara göre toplu taşıma kullanma ihtimali 0.142 kat, yolculuk süresi 12-17 dk arasında olanların yolculuk süresi $60 \mathrm{dk}$ ve üzeri olanlara göre toplu taşıma kullanma ihtimali 0.488 kat, yolculuk süresi $18-23 \mathrm{dk}$ arasında olanların yolculuk süresi $60 \mathrm{dk}$ ve üzeri olanlara göre toplu taşıma kullanma ihtimali 0.48 kat, yolculuk süresi 24-29 dk arasında olanların yolculuk süresi $60 \mathrm{dk}$ ve üzeri olanlara göre toplu taşıma kullanma ihtimali 0.343 kat, yolculuk süresi 30-35 dk arasında olanların yolculuk süresi $60 \mathrm{dk}$ ve üzeri olanlara göre toplu taşıma kullanma ihtimali 1.476 kat, yolculuk süresi 36-41 dk arasında olanların yolculuk süresi $60 \mathrm{dk}$ ve üzeri olanlara göre toplu taşıma kullanma ihtimali 1.299 kat daha fazladır. 
Çizelge 6. Bayburt ili için ikili lojistik regresyon model sonuçları

\begin{tabular}{|c|c|c|c|c|c|c|}
\hline Değişkenler & B & S. hata & Wald & df & Sig. & $\operatorname{Exp}(B)$ \\
\hline \multicolumn{7}{|l|}{ Cinsiyet } \\
\hline Kadın & 0.642 & 0.206 & 9.720 & 1 & 0.002 & 1.901 \\
\hline Erkek & \multicolumn{3}{|c|}{ Referans Kategori } & & & \\
\hline Yaşı & & & 6.706 & 5 & 0.243 & \\
\hline $0-11$ & 2.006 & 1.096 & 3.348 & 1 & 0.067 & 7.433 \\
\hline $12-23$ & 1.477 & 1.074 & 1.889 & 1 & 0.169 & 4.380 \\
\hline $24-35$ & 0.973 & 1.063 & 0.838 & 1 & 0.360 & 2.646 \\
\hline $36-47$ & 1.315 & 1.055 & 1.552 & 1 & 0.213 & 3.723 \\
\hline $48-59$ & 1.122 & 1.068 & 1.103 & 1 & 0.294 & 3.070 \\
\hline $60>$ & \multicolumn{6}{|c|}{ Referans Kategori } \\
\hline Ĕ̈itimdurumu & & & 3.723 & 8 & 0.881 & \\
\hline Çocuk-kreş & 0.283 & 41703.708 & 0.000 & 1 & 1.000 & 1.327 \\
\hline Okur yazar değil & 19.430 & 40205.075 & 0.000 & 1 & 1.000 & $\begin{array}{l}274279 \\
327.534\end{array}$ \\
\hline Okur Yazar & 20.977 & 57881.671 & 0.000 & 1 & 1.000 & $\begin{array}{r}1288950 \\
198.966 \\
\end{array}$ \\
\hline İlkokul & 19.257 & 40205.075 & 0.000 & 1 & 1.000 & $\begin{array}{r}230824 \\
058.204 \\
\end{array}$ \\
\hline Ortaokul & 18.973 & 40205.075 & 0.000 & 1 & 1.000 & $\begin{array}{l}173663 \\
194.461 \\
\end{array}$ \\
\hline Lise & 19.337 & 40205.075 & 0.000 & 1 & 1.000 & $\begin{array}{l}250006 \\
334.108 \\
\end{array}$ \\
\hline Üniversite & 18.895 & 40205.075 & 0.000 & 1 & 1.000 & $\begin{array}{r}160656 \\
428.554 \\
\end{array}$ \\
\hline Yüksekokul & 19.090 & 40205.075 & 0.000 & 1 & 1.000 & $\begin{array}{l}195214 \\
766.873 \\
\end{array}$ \\
\hline Lisansüstü & Referans Kat & & & & & \\
\hline \multicolumn{7}{|c|}{ Sürücü Belgesi Sahipliği } \\
\hline SB yok & -0.106 & 0.278 & 0.146 & 1 & 0.703 & 0.899 \\
\hline SB var & \multicolumn{6}{|c|}{ Referans Kategori } \\
\hline Yolculuk amacı & & & 13.528 & 7 & 0.060 & \\
\hline Ev & -15.945 & 19663.363 & 0.000 & 1 & 0.999 & 0.000 \\
\hline İş & 2.919 & 1.047 & 7.770 & 1 & 0.005 & 18.524 \\
\hline Eğitim & 3.156 & 1.070 & 8.696 & 1 & 0.003 & 23.470 \\
\hline Sağlık & -16.593 & 10879.568 & 0.000 & 1 & 0.999 & 0.000 \\
\hline Alışveriş & 1.788 & 1.130 & 2.503 & 1 & 0.114 & 5.979 \\
\hline İş Takibi & -16.237 & 22645.768 & 0.000 & 1 & 0.999 & 0.000 \\
\hline Akraba Ziyareti & -16.310 & 4583.569 & 0.000 & 1 & 0.997 & 0.000 \\
\hline Diğer & \multicolumn{6}{|c|}{ Referans Kategori } \\
\hline Yolculuksüresi & & & 51.631 & 9 & 0.000 & \\
\hline 0-5 Dakika & -1.087 & 23388.661 & 0.000 & 1 & 1.000 & 0.337 \\
\hline 6-11 Dakika & -1.955 & 0.877 & 4.964 & 1 & 0.026 & 0.142 \\
\hline 12-17 Dakika & -0.717 & 0.854 & 0.705 & 1 & 0.401 & 0.488 \\
\hline 18-23 Dakika & -0.734 & 0.864 & 0.723 & 1 & 0.395 & 0.480 \\
\hline 24-29 Dakika & -1.071 & 0.902 & 1.410 & 1 & 0.235 & 0.343 \\
\hline 30-35 Dakika & 0.389 & 0.904 & 0.185 & 1 & 0.667 & 1.476 \\
\hline 36-41 Dakika & 0.262 & 0.869 & 0.091 & 1 & 0.763 & 1.299 \\
\hline 42-47 Dakika & -20.285 & 40192.970 & 0.000 & 1 & 1.000 & 0.000 \\
\hline 48-53 Dakika & -19.360 & 15260.535 & 0.000 & 1 & 0.999 & 0.000 \\
\hline $60>$ Dakika & \multicolumn{6}{|c|}{ Referans Kategori } \\
\hline Constant & -24.409 & 40205.075 & 0.000 & 1 & 1.000 & 0.000 \\
\hline
\end{tabular}

(B: Regresyon Katsayıları, S.E.: Standart Hata, Wald: istatistiği, df: serbestlik derecesi, sig.: anlamlılık düzeyi, Exp(B): üstel B değerleri) 
Çizelge 7'de üç farklı gelişmişlik düzeyindeki il için oluşturulan toplu taşıma kullanım model özetleri sunulmuştur. $\mathrm{Bu}$ modellerde Ankara ilinde toplu taşıma kullanımının \% 45.5'i, Erzurum ilinde toplu taşıma kullanımının \% 38'i ve Bayburt ilinde ise \% 25'i bağımsız değişkenler tarafından açıklanmıştır (Nagelkerke $R^{2}$ ).

Çizelge 7. İller için oluşturulan ikili lojistik regresyon model özetleri

\begin{tabular}{|l|r|r|r|}
\hline \multicolumn{1}{|c|}{ Iller } & $\mathbf{- 2}$ Log likelihood & Cox \& Snell $\boldsymbol{R}^{\mathbf{2}}$ & Nagelkerke $\boldsymbol{R}^{\mathbf{2}}$ \\
\hline Ankara & 1594.660 & 0.321 & 0.455 \\
\hline Erzurum & 1414.425 & 0.283 & 0.380 \\
\hline Bayburt & 799.589 & 0.141 & 0.248 \\
\hline
\end{tabular}

Cox \& Snell $\mathrm{R}^{2}=1-\left\{\frac{L\left(\mathrm{M}_{\text {intercept }}\right)}{L\left(\mathrm{M}_{\text {full }}\right)}\right\}^{2 / N}$

Nagelkerke $\mathrm{R}^{2}=\frac{1-\left\{\frac{L\left(\mathrm{M}_{\text {intercept }}\right)}{L\left(\mathrm{M}_{\text {full }}\right)}\right\}^{2 / N}}{1-L\left(M_{\text {intercept }}\right)^{2 / N}}$

Açıklayıcılık katsayılarının $\left(\mathrm{R}^{2}\right)$ formülasyonları eşitlik (3) ve (4) de verilmiştir. Eşitliklerde; L= likelihood değeri (olabilirlik oranı), =Yordayıcılar ile model, =yordayıcılarsız model ifade etmektedir.

\section{SONUÇLAR VE ÖNERILER}

Bu çalışmada Türkiye' de gelişmişlik indekslerine göre seçilen üç farklı gelişmişlik düzeyindeki illerde toplu taşıma kullanımı incelenmiştir. $\mathrm{Bu}$ illerde yaptırılan hanehalkı ulaşım anketleri sonucu elde edilen verilere göre toplu taşıma kullanım oranının en yüksek olduğu il gelişmekte olan il grubundan seçilen Erzurum ili, ikincisi gelişmiş il olan Ankara ili ve üçüncüsü ise gelişmemiş il olan Bayburt ilidir. Toplu taşıma kullanıyor musunuz? (evet- hayır) sorusunun bağımlı değişken olarak belirlendiği ikili lojistik regresyon model her üç il içinde ayrı ayrı oluşturulmuştur. İkili lojistik regresyon analiz sonuçlarına göre Ankara ili için oluşturulan toplu taşıma kullanım modelinde ehliyet sahipliği, yolculuk amacı ve yolculuk süresi değişkenleri anlamlı değişken, Erzurum ili için oluşturulan toplu taşıma kullanım modelinde eğitim durumu, ehliyet sahipliği, yolculuk amacı ve yolculuk süresi değişkenleri anlamlı değişken, Bayburt ili için oluşturulan toplu taşıma kullanım modelinde ise cinsiyet ve yolculuk süresi bağımsız değişkenleri anlamlı değişken olarak elde edilmiştir.

Üç farklı gelişmişlik düzeyindeki illerde yolculuk süresi bağımsız değişkeni ortak anlamlı değişkendir. Literatürde toplu taşıma kullanımı ile ilgili birçok çalışma bulunmasına rağmen farklı gelişmişlik düzeyindeki illerin toplu taşıma kullanımını inceleyen bir çalışma bulunmamaktadır. Bu çalışma sonucu elde edilen veriler 1şığında farklı gelişmişlik düzeyindeki illerde yaşayan bireylerin toplu taşıma kullanımında etkili olan parametreler farklı olduğundan dolayı gelişmişlik düzeyi farklı illerde toplu taşıma yönlendirmeleri için alınacak önlemler ve çözümler de farklı olmalıdır.

\section{TEŞEKKÜR}

Bu çalışmada kullanılan veri seti, 2014/189 nolu Atatürk Üniversitesi Bilimsel Araştırma Projesinden sağlanan destekle yaptırılan anket çalışması ile oluşturulmuştur. Anılan destek ve katkı dolayısıyla, Atatürk Üniversitesi'ne ve anket çalışmasını gerçekleştiren ASY Eğitim ve Danışmanlık şirketine teşekkür ederim. 


\section{KAYNAKLAR}

Buehler R, Hamre A, 2015. The multimodal majority? Driving, walking, cycling, and public transportation use among American adults. Transportation, 42: 1081-1101.

Field A, 2005. Discovering Statistics Using SPSS. Second Edition, London, England. 266 p.

Gül E, Çevik B, 2014. Türkiye'de İllerin Gelişmişlik Düzeyi Araştırması. Türkiye İş Bankası, İktisadi Araştırmalar Bölümü, İstanbul.

Kalaycı Ş, 2008. SPSS Uygulamalı Çok Değişkenli İstatistiki Teknikler.3. Bask1, Ankara, Türkiye. 273 p.

Kennedy C A, 2002. A comparison of the sustainability of public and private transportation systems: Study of the Greater Toronto Area. Transportation, $29: 459-493$.

Kılınçaslan, T. 2012. Kentsel Ulaşım. 1. Baskı, İstanbul, Türkiye. $174 \mathrm{p}$.
Kuhnimhof T, Chlond B, Von der Ruhren S, 2006. Users of transport modes and multimodal travel behavior steps toward understanding travelers' options and choices. Transportation Research Record: Journal of the Transportation Research Board, 1985: 40-48.

Miller P, Barros A G, Kattan L, Wirasinghe S C, 2016. Public Transportation and Sustainability: A Review. KSCE Journal of Civil Engineering, 20 : 1076-1083.

Namgung M,Akar G, 2014. Role of Gender and Attitudes on Public Transportation Use. Transportation Research Record: Journal of the Transportation Research Board, 2415: 136-144.

Şimşekoğlu Ö, Nordfjærn T, Rundmo T, 2015. The role of attitudes, transport priorities, and car use habit for travel mode use and intentions to use public transportation in an urban Norwegian public. Transport Policy, 42: 113-120. 